\title{
Research on stimulation of injection and production capacity for single well in underground gas storage
}

\author{
Chen $\mathrm{Li}^{1}$, Xiaoyong Wen ${ }^{1}$, Zhihao Shen ${ }^{1}, \mathrm{Li} \mathrm{Li}^{1}$, Peng Liu ${ }^{2}$ and Hu Peng ${ }^{3, *}$ \\ ${ }^{1}$ Oil and Gas Technology Research Institute of Changqing Oilfield Company, China \\ ${ }^{2}$ The Second Gas Production Plant of Changqing Oilfield Company, China \\ ${ }^{3}$ School of Chengdu University of Technology, Chengdu, China
}

\begin{abstract}
Underground gas storage is the best choice for natural gas resource reserve and peak value. Storage capacity of underground gas storage and single well injection and production capacity are the key indicators of shaving capacity. This paper focuses on research of expansion of gas storage and the stimulation of injection and production capacity of single well of a basin in Western China. Firstly, based on the study of two-phase seepage law of gas and water, a numerical simulation model coupling high velocity non-Darcy effect and gas-water two phase seepage is established; Secondly, the influencing factors of single well injection and production capacity are analysed. Finally, acidizing can effectively improve the single well injection and production capacity of well. The numerical simulation result shows that the injection and production differential pressure is reduced by $70 \%$, and gas injection and production volume are increased by $14.8 \%$ and $26.9 \%$.
\end{abstract}

Key words: underground gas storage; seepage model; high velocity non-Darcy; numerical simulation.

\section{Introduction}

As a clean energy, natural gas is seriously uneven in distribution, and is easily affected by climatic conditions, civil consumption and other factors. Underground gas storage is the efficient measurement choice for natural gas resource reserve and peak value. Underground gas storage can be divided three types: depleted oil and gas fields, water bearing structures and salt caves. Underground gas storage can solve the problem of uneven urban gas consumption, which plays a important role for seasonal peak shaving. The capacity, safety and economy of underground gas storage are better than those of ground metal gas storage tanks.

Storage capacity is the gas volume corresponding to the movable gas of formation affected by pressure in the process of high-velocity injection and production. Storage capacity, single well injection and production capacity are key indicators of shaving. Improving the injection and production capacity of single well is an efficient measure for expansion of gas storage capacity. This paper focuses on the measures to improve the injection and production capacity of a single well in an underground gas reservoir reconstructed from a depleted gas reservoir in a basin in Western China. Firstly, numerical simulation model of single well in the basis of gas-water two-phase seepage is established. Secondly, the key factors affecting the injection and production capacity of a single well are analysed. The result of numerical stimulation shows that acidizing can effectively improve the injection and production capacity of a single well.

\section{Numerical simulation model of single well}

\subsection{Physical model}

A underground gas storage in western China is reconstructed from depleted gas reservoir, its lithology belongs to tight sandstone, and the micro fractures in the reservoir are not developed. In the process of gas reservoir injection and production, especially during gas supplying in winter, the influence of high velocity non-Darcy effect on gas seepage can not be ignored. When considering the high velocity non-Darcy effect and gas-water two-phase flow, the assumptions of the physical model of gas transport in reservoir are as follows:

(1) There are only two kinds of fluids in gas reservoir, natural gas and water, and the gas phase is insoluble in water phase;

(2) The compressibility coefficient of slightly compressible rock and water are constant, and gas is easily compressible;

(3) The effects of capillary force and gravity of two-phase are considered in the matrix system;

* Corresponding author: 201704010309@stu.cdut.edu.cn 
(4) The influence of high velocity non-Darcy effect is considered in gas flow, and the water phase is Darcy seepage.

\subsection{Mathematical model}

(1) Seepage control equation

Based on the principle of mass conservation, the continuity equation of gas-water two-phase flow can be described as follow:

$$
\begin{gathered}
-\nabla \cdot\left(\rho_{\mathrm{g}} v_{\mathrm{g}}\right)+\delta_{\mathrm{g}} q_{\mathrm{g}}=\frac{\partial\left(\varphi \rho_{\mathrm{g}} S_{\mathrm{g}}\right)}{\partial \tau} \\
-\nabla \cdot\left(\rho_{\mathrm{w}} v_{\mathrm{w}}\right)+\delta_{\mathrm{w}} q_{\mathrm{w}}=\frac{\partial\left(\varphi \rho_{\mathrm{w}} S_{\mathrm{w}}\right)}{\partial \tau}
\end{gathered}
$$

Where, $\varphi$ is porosity, $\% ; \rho_{\mathrm{g}}, \rho_{\mathrm{W}}$ are density of gas and water in reservoir pressure condition, $\mathrm{kg} / \mathrm{m}^{3} ; v_{\mathrm{g}}$ and $v_{\mathrm{w}}$ are seepage velocity, $\mathrm{m} / \mathrm{s} ; s_{\mathrm{g}}$ is gas saturation, $\% ; s_{\mathrm{w}}$ is water saturation; $q_{\mathrm{g}}$ and $q_{\mathrm{w}}$ are injection and production volume in micro element, injection is positive and recovery is negative $\left(\mathrm{kg} /\left(\mathrm{m}^{3} \cdot \mathrm{s}\right)\right) ; \delta \mathrm{g}$ and $\delta \mathrm{w}$ are well point function, at the well point $\delta=1$, and at non well point, $\delta \mathrm{g}=0$.

The influence of high velocity non-Darcy effect on gas transport in porous medias can't be ignored, in the process of gas injection and production of underground gas storage. According to Forchheimer equation, the expression of gas motion equation considering the influence of high velocity non-Darcy effect is shown as follows:

$$
\nabla p=\frac{\mu_{\mathrm{g}}}{K_{\mathrm{g}}}{\stackrel{\mathrm{r}}{v_{\mathrm{g}}}}+\beta \rho{\stackrel{\mathrm{r}}{v_{\mathrm{g}}}}^{2}
$$

In order to describe high velocity nonlinear seepage in porous medias, turbulence factor $\xi$ is introduced in the motion equation. The expression of turbulence factor is as follows:

$$
\xi=\frac{1}{1+\beta \rho v_{\mathrm{g}}^{\mathrm{r}} K_{\mathrm{g}} / \mu_{\mathrm{g}}}
$$

The following empirical formula of non-Darcy coefficient for multiphase flow $\beta$ can be described as follow:

$$
\beta=\frac{6.92 \times 10^{10}}{\left(K K_{\mathrm{rg}}\right)^{0.5}\left[\phi\left(1-S_{\mathrm{w}}\right)\right]^{1.5}}
$$

Therefore, the motion equation of gas considering only considering the influence of high velocity non-Darcy can be rewritten as:

$$
\stackrel{\mathrm{r}}{\mathrm{r}}_{\mathrm{g}}=-\frac{K_{\mathrm{g}} \xi}{\mu_{\mathrm{g}}} \nabla p
$$

Then the governing equations of gas-water two-phase transport in the rock of underground gas storage are shown as:

$$
\left\{\begin{array}{l}
\nabla \cdot \frac{K K_{r w}}{\mu_{w} B_{w}}\left(\nabla p_{w}-\gamma_{w} \nabla D\right)+\delta_{w} q_{w}=\frac{\partial}{\partial \tau}\left(\frac{\varphi S_{w}}{B_{w}}\right) \\
\nabla \cdot \xi \frac{K K_{\text {rg }}}{\mu_{g} B_{g}}\left(\nabla p_{g}-\gamma_{g} \nabla D\right)+\nabla \cdot \frac{R^{\prime} K K_{n v}}{\mu_{w} B_{w}}\left(\nabla p_{w}-\gamma_{w} \nabla D\right)+\delta_{g} q_{g}=\frac{\partial}{\partial \tau}\left(\frac{\varphi S_{g}}{B_{g}}+\frac{\varphi R^{\prime} S_{w}}{B_{w}}\right)
\end{array}\right.
$$

Where $\mathrm{D}$ is vertical height below seepage datum, $\mathrm{m}$. Gas and water saturation satisfy the following equation:

$$
S_{g}+S_{w}=1
$$

The capillary pressure satisfies the following equation:

$$
p_{c}=p_{g}-p_{w}=f\left(S_{w}\right)
$$

Where pc is capillary force between gas phase and water phase.

(2) Initial conditions

In the process of injecting gas into the underground gas storage, a certain time is selected as the initial time. It is necessary to determine the initial distribution of pressure and saturation at various points in the gas storage. Then, the distribution of pressure and fluid saturation in the gas storage at the initial time is shown as follows:

$$
\begin{aligned}
& \left.p_{\mathrm{g}}(x, y, z)\right|_{r=0}=f_{1}(x, y, z) \\
& \left.S_{\mathrm{w}}(x, y, z)\right|_{\tau=0}=f_{2}(x, y, z)
\end{aligned}
$$

(3) Outer boundary condition

A underground gas storage is a closed sandstone gas reservoir without marginal and bottom water. Therefore, the outer boundary conditions can be written as follows:

$$
\left.\frac{\partial p}{\partial n}\right|_{\Gamma}=0
$$

Where $\left.\frac{\partial p}{\partial n}\right|_{\Gamma}$ represents derivative of the pressure on the normal direction of outer boundary; $\Gamma$ is the outer boundary of the gas reservoir.

(4) Inner boundary condition

When the well production rate is constant, Dirac function can be used to deal with the well point due to wellbore radius is particularly smaller than well spacing. The production of grid blocks can be expressed as:

$$
q_{\mathrm{g}}(i, j, k, t)=q_{\mathrm{g}}(t) \delta(i, j, k)
$$

Where $\delta(\mathrm{i}, \mathrm{j}, \mathrm{k})$ is Dirac function, which is equal to 1 when well is in the grid block, and equal to 0 when there are no wells.

When the bottom hole flow pressure is constant, the production in the grid block (wells in the grid block) is satisfied steady flow. According to Peaceman model, the production of wells in the grid block can be expressed as: 


$$
\begin{gathered}
q_{\mathrm{g}}=\frac{2 \pi K K_{\mathrm{rg}} h \alpha \xi}{\mu_{\mathrm{g}} B_{\mathrm{g}}\left[\ln \left(r_{\mathrm{e}} / r_{\mathrm{w}}\right)+s\right]} \cdot\left(p_{\mathrm{g}}-p_{\mathrm{wTg}}\right) \\
q_{\mathrm{w}}=\frac{2 \pi K K_{\mathrm{rw}} h \alpha}{\mu_{\mathrm{w}} B_{\mathrm{w}}\left[\ln \left(r_{\mathrm{c}} / r_{\mathrm{w}}\right)+s\right]} \cdot\left(p_{\mathrm{w}}-p_{\mathrm{wfw}}\right)
\end{gathered}
$$

Where $\mathrm{h}$ is effective thickness of gas reservoir, $\mathrm{m}$ ); re is equivalent radius of grid block, $\mathrm{m}$; $\mathrm{S}$ is skin factor; $\alpha$ is unit conversion factor, which is equal to 0.0864 .

\subsection{Numerical simulation model}

Based on mathematical model of gas-water two-phase flow in gas storage, the solution of the numerical model can be deduced by finite difference method. The formation parameters of underground gas storage is shown in table 1.

Table 1. Parameters of reservoir for model construction

\begin{tabular}{|c|c|c|c|c|c|}
\hline Parameters & Value & Parameters & Value & Parameters & Value \\
\hline $\begin{array}{c}\text { Reservoir pressure } \\
(\mathrm{MPa})\end{array}$ & 27.7 & $\begin{array}{c}\text { Temperature } \\
(\mathrm{K})\end{array}$ & 364 & $\begin{array}{c}\text { Porosity } \\
(\%)\end{array}$ & 6.2 \\
\hline $\begin{array}{c}\text { Permeability } \\
(\mathrm{mD})\end{array}$ & 3.8 & $\begin{array}{c}\text { Gas saturation } \\
(\%)\end{array}$ & 68 & $\begin{array}{c}\text { Depth of } \\
\text { reservoir }(\mathrm{m})\end{array}$ & 2800 \\
\hline $\begin{array}{c}\text { Length of reservoir } \\
(\mathrm{m})\end{array}$ & 2000 & $\begin{array}{c}\text { Width of } \\
\text { reservoir }(\mathrm{m})\end{array}$ & 1000 & $\begin{array}{c}\text { Thickness } \\
(\mathrm{m})\end{array}$ & 10.1 \\
\hline
\end{tabular}

The relative permeability curve and rock compressibility coefficient curve used in the digital simulation process are shown in Figure 1.

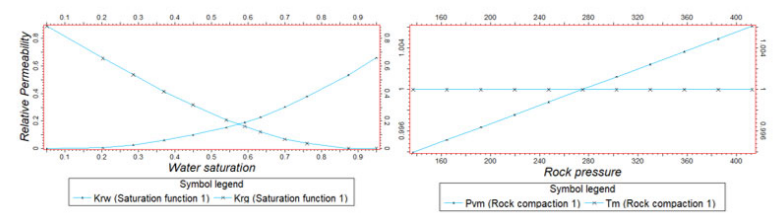

Figure 1. Relative permeability curve and reservoir compressibility for model construction

The numerical simulation model single well in underground gas storage is as shown in Figure.2, the horizontal section length is $1000 \mathrm{~m}$. The actual size of gas reservoir established in this paper is $2000 \mathrm{~m} \times 1000 \mathrm{~m} \times$ $100 \mathrm{~m}$, and the gas reservoir is divided into $42 \times 24 \times 1$ grids.

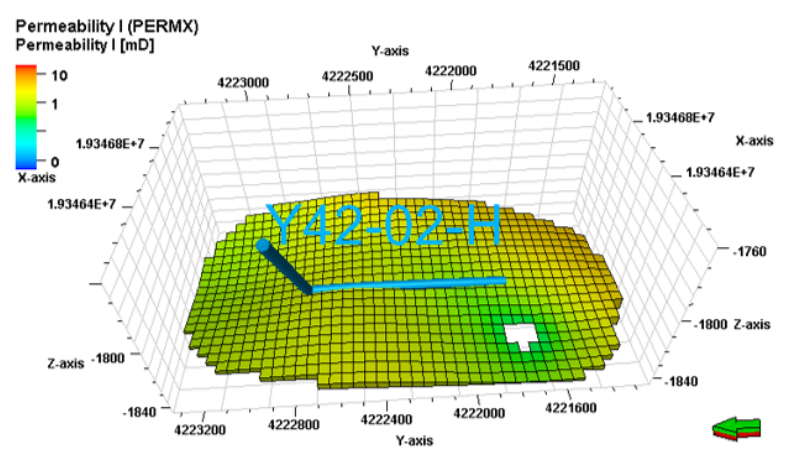

Figure 2. Numerical simulation model of single well in underground gas storage

\section{Measurement of simulation}

Figure 3 shows log-log plot of pressure and pressure derivative via time of pressure build up test of a gas well in the gas storage. The skin factor of the well is 5, indicating that there is existing high pollution near the wellbore.

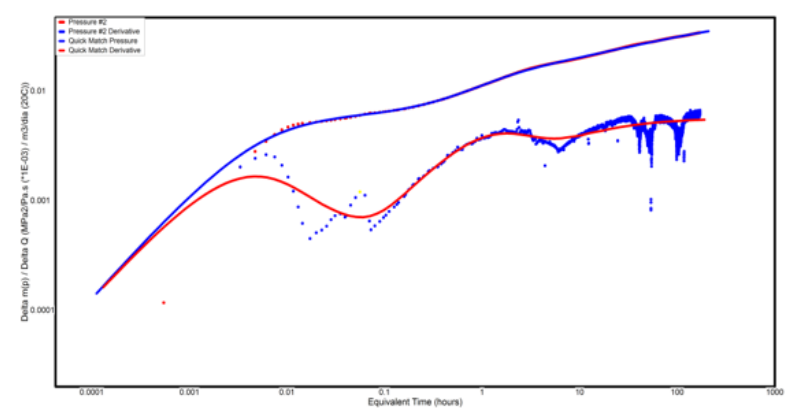

Figure 3. Double logarithmic curve of pressure and pressure derivative with. time

As shown in equation (14) and (15), the factors affecting the injection production capacity of gas wells including reservoir permeability, thickness, skin factor, wellbore radius, etc. For gas wells, the reservoir permeability and thickness can't be changed. Removing the pollution near the wellbore can improve the productivity of a single well. Acidizing is usually used for plug-release in the formation nearby wellbore. The purpose of acidizing is reducing skin factor to increase production capacity of gas well.

\section{Result of numerical simulation}

Acidizing can reduce skin factor of gas well, so the skin factors of acidized and none acidized gas wells in numerical simulation model are 0 and 3. The reservoir parameters used in simulation models are shown in table 1.The injection and production rate are respectively $33.64 \times 104 \mathrm{~m} 3 / \mathrm{d}$ and $60 \times 104 \mathrm{~m} 3 / \mathrm{D}$ in the numerical simulation model, and simulation results are shown in figure 4 and 5. Figure 4 shows the bottom hole pressure and flow pressure in the process of injection and production. Simulation results shows that the pressure difference between reservoir pressure and flowing pressure is $5 \mathrm{MPa}$ for gas well without acidizing. After acidizing, pressure difference in the process of injection and production is reduced to $1.5 \mathrm{MPa}$.
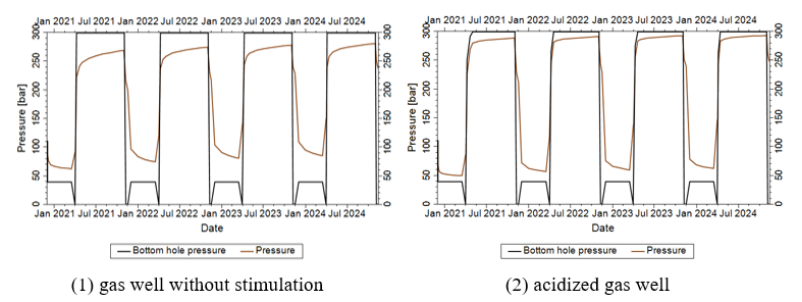

Figure 4. Pressure difference between reservoir pressure and flowing pressure in the process of injection and production 
Figure 5 shows the cumulative injection and production gas volume of acidized and none acidized gas well. The cumulative injection and production gas volume of the gas well without stimulation are $1.49 \times 10^{8} \mathrm{~m}^{3}$ and $4.95 \times 10^{7} \mathrm{~m}^{3}$, respectively. The cumulative injection and production gas volume of the acidized gas well are $1.71 \times 10^{8} \mathrm{~m}^{3}$ and $6.28 \times 10^{7} \mathrm{~m}^{3}$, respectively. After acidizing, the injection and production capacity are increased by $14.8 \%$ and $26.9 \%$ respectively.
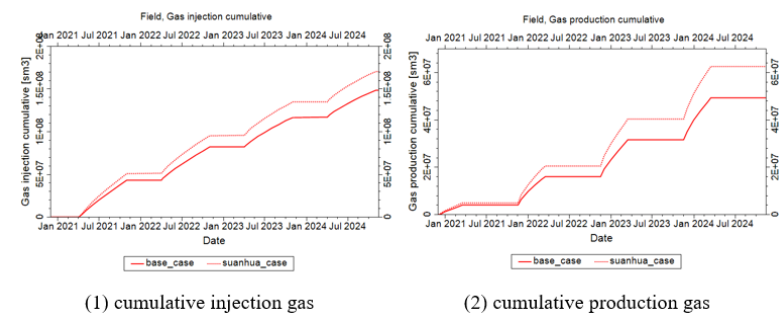

Figure 5. simulation results of cumulative injection production gas volume between acidized and none acidized gas well

\section{Conclusion}

(1) Based on multiphase seepage theory, a numerical simulation model considering high velocity non-Darcy effect and gas-water two-phase seepage is established.

(2) Acidizing is important measures to improve the injection production capacity of single wells in underground gas storage. After acidizing, the differential pressure in the process of injection and production of gas wells in underground gas storage are decreased by $70 \%$, and the injection and production capacity increased by $14.8 \%$ and $26.9 \%$.

\section{References}

1. Zhu S, Sun J, Wei G, et al. Numerical simulationbased correction of relative permeability hysteresis in water-invaded underground gas storage during multicycle injection and production[J]. Petroleum Exploration and Development, 2021, 48(1):190-200.

2. Wang T, Yan X, Yang H, et al. A new shape design method of salt cavern used as underground gas storage[J]. Applied Energy, 2013, 104(APR.):50-61.

3. Nagelhout A, Roest J. Investigating fault slip in a model of an underground gas storage facility[J]. International Journal of Rock Mechanics \& Mining Sciences, 1997, 34(3-4):212.e1-212.e14.

4. Ma H, Yang C, Li Y, et al. Stability evaluation of the underground gas storage in rock salts based on new partitions of the surrounding rock[J]. Environmental Earth Sciences, 2015, 73(11):6911-6925.

5. Yang M, Guan B. Coupling model of underground gas-storage caverns and its application in engineering[J]. Chinese Journal of Rock Mechanics and Engineering, 2003.

6. Wang T, Yang C, Yan X, et al. Dynamic response of underground gas storage salt cavern under seismic loads $[\mathrm{J}]$. Tunnelling and Underground Space Technology, 2014, 43(7):241-252.

7. Xin S. Optimum method for underground gas storage projects based on fuzzy comprehensive evaluation[J]. Acta Petrolei Sinica, 2006. 